\title{
Cost-benefit analysis as a tool for measuring economic impacts of local food systems: Case study of an institutional sourcing change
}

\author{
Zoë T. Plakias * \\ The Ohio State University
}

Submitted September 4, 2020 / Revised December 22, 2020, and January 16, 2021 / Accepted February 3, 2021 /

Published online June 8, 2021

Citation: Plakias, Z. T. (2021). Cost-benefit analysis as a tool for measuring economic impacts of local food systems:

Case study of an institutional sourcing change. Journal of Agriculture, Food Systems, and Community Development, 10(3),

161-185. https://doi.org/10.5304/jafscd.2021.103.011

Copyright ( 2021 by the Author. Published by the Lyson Center for Civic Agriculture and Food Systems. Open access under CC-BY license.

\begin{abstract}
Universities continue to expand their local food sourcing, but the impacts of these sourcing changes are ambiguous. Some academics have measured these impacts using input-output analysis methods to track economic indicators that may be of interest to local communities. However, these studies do not capture nonmarket benefits of local food system investments or answer the broader question of whether local sourcing benefits society as a whole, both of which can be addressed using cost-benefit analysis. This paper explores cost-benefit analysis as an additional tool for measuring the economic impacts of local food investments, using a sourcing change by The Ohio State University as a case study. It builds on recent theoretical applied economics literature on the welfare impacts of local food sourcing and sheds light on important trade-offs of local sourcing that institutions and
\end{abstract}

* Zoë T. Plakias, Assistant Professor, Department of Agricultural, Environmental and Development Economics, The Ohio State University; 323 Agricultural Administration Building, 2120 Fyffe Road; Columbus, OH 43210 USA; plakias.2@,osu.edu other buyers may want to consider. Employing data provided by Ohio State University Dining Services and the U.S. Department of Agriculture, I use a Monte Carlo simulation approach that accounts for uncertainty and allows for exploration of many scenarios. In more than half of the scenarios, local sourcing yields a net loss to society. However, additional research is needed by economists and others to enable local food system stakeholders to more easily and accurately conduct this work and add cost-benefit analysis to their project evaluation toolkit.

\section{Keywords}

Local Food, Local Sourcing, Farm-to-Institution, Welfare Analysis, Cost-Benefit Analysis, InputOutput Analysis, Economic Impact Analysis, Higher Education

\footnotetext{
Disclosures

I am a faculty member in an academic unit in The Ohio State University to which this paper refers, and the data used in this paper were obtained from Ohio State University Dining Services, another unit of the university. Also, I am a resident of the geographic area discussed in the paper.
} 


\section{Introduction}

While still a relatively small portion of total food sales, total local (or direct) food sales appear to be increasing in the U.S. In 2017, farmers earned US $\$ 11.8$ billion in revenue from direct sales to consumers, retailers, institutions, and intermediaries with regional and local marketing (U.S. Department of Agriculture, National Agricultural Statistics Service [USDA NASS], 2019). Although not directly comparable to prior estimates due to differences in data sources, this number represents an increase from prior revenue estimates of US $\$ 8.7$ billion in 2015 and US $\$ 6.1$ billion in 2012 (Low et al., 2015; USDA NASS, 2016). As local food sales increase, a significant effort is being undertaken by researchers across disciplines to rigorously measure and account for the impacts of these sales. Much of this research is occurring on university campuses. But that is not the only activity related to local food systems taking place on campus-universities increasingly recognize the roles that they play as buyers and investing in local food systems directly.

Thinking and writing about the role of large institutions in local food systems is not new. Many agricultural economists and researchers in other disciplines have explored the barriers and opportunities associated with farm-to-institution sales for universities in particular (e.g., Feenstra et al., 2011; Hardesty, 2008; Leib et al., 2012; Ng et al., 2010). In addition, some agricultural economists are developing tools to help communities, institutions, and other food system stakeholders better understand the economic impacts of their decisions and investments related to local food systems. For example, the Economics of Local Food Systems toolkitdeveloped by academic and government economists and published by the USDA Agricultural Marketing Service (AMS) — provides food system stakeholders with a step-by-step process for measuring the economic impacts of their food system projects using the common input-output methodology (Thilmany McFadden et al., 2017). However, some scholars suggest a need remains for more rigorous assessment of the impacts of local food investments than the existing method of inputoutput analysis (Deller et al., 2017; Goldenberg \& Meter, 2019).

In this paper, I discuss an alternative economic project evaluation method-cost-benefit analysis. Economic impact analyses using input-output models provide estimates of the impacts of local food system investments on key economic indicators like employment and household income. In contrast, cost-benefit analysis allows us to answer the broader question-do local food system investments benefit society as a whole-by allowing for the inclusion of nonmarket impacts of local food systems and expansion of the community of interest to all of society. To explore how the process of cost-benefit analysis can be used by institutions and others, I consider Ohio State University (OSU) Dining Services' decision to source a local product, sweet potatoes, for its dining halls in lieu of sourcing entirely from nonlocal producers. Specifically, the research question addressed in this article is: What is the net benefit to society of OSU Dining Services changing from a nonlocal to a local supplier for sweet potatoes? This work explores how cost-benefit analysis can be used to give food service managers and other food system stakeholders a better understanding of the trade-offs inherent in their local food system investments and suggests important areas for future research to enable more comprehensive and accurate cost-benefit analyses going forward.

To my knowledge, this work is the first published cost-benefit analysis of an institutional investment in local food systems. Lack of prior literature is not surprising, as presumably maximizing welfare-an economic term for societal benefit-is not the primary goal of many local food system stakeholders. In addition, as discovered in the course of this work, there are substantial gaps in data availability that may limit the usefulness of cost-benefit analysis at present. Nevertheless, in order to build capacity to employ this type of analysis in the future it is useful to explore this approach and identify specific strengths, weaknesses, and areas for future study.

This work also builds on recent theoretical work on local foods. In their 2017 paper in the American Journal of Agricultural Economics, Winfree and Watson explored the welfare impacts of "Buy Local" programs using a theoretical approach, building a two-region theoretical economic model to demonstrate the welfare impacts of local food 
investments and to determine under what conditions local food system investments would be welfare-enhancing for society as a whole. With this model, they demonstrated that in the presence of externalities (external costs or benefits incurred by third parties) or market power (the ability of buyers or sellers to set price) "Buy Local" programs could be welfare-enhancing. However, in other situations the net impact on society was unequivocally negative. This paper complements Winfree and Watson's work by considering how the type of welfare analysis they considered might be conducted for a specific local food system investment. Cost-benefit analysis is the methodology of conducting applied welfare analysis in a specific empirical setting.

The particular setting considered-with the university as a single buyer-is one possible setting in which to use cost-benefit analysis, and as with any setting has both its advantages and disadvantages. One advantage is that the opportunity cost of purchasing the local product (i.e., what product the buyer switches away from) is quite clear in the university setting; in contrast, it can be difficult to know what a consumer at a farmers market or similar venue would have purchased instead of a local product (O'Hara \& Pirog, 2013). On the other hand, understanding the benefits accruing to students in an all-you-can-eat dining hall setting presents a challenge relative to settings where consumers face more price variation (as in most market environments). While the specific setting examined quite obviously lacks external validity, an important insight of Winfree and Watson's workand a component of local food systems understood widely by food system stakeholders-is that each setting is different. ${ }^{1}$ Thus, while the quantitative results should not be assumed to hold for other products and/or regions, the contribution of this work is to explore the process of conducting ap- plied welfare analysis in the context of a specific local food system investment and provide an example for others.

The cost-benefit analysis conducted in this paper consists of several steps. First, the groups impacted by the sourcing change are defined. Second, the welfare impacts on each of these groups are described and measured using estimates from prior literature and data provided by OSU Dining Services and its vendors. Then these data are used to parameterize a Monte Carlo simulation model and develop a range of estimates for the net benefits of this sourcing change in its first year. I find that the net benefits to society of this sourcing change are positive in less than $50 \%$ (of 10,000 ) cases and highlight some excluded impacts (e.g., environmental and social) which could affect these results. These results emphasize the importance of understanding the specific ways that local and nonlocal markets may be impacted in a particular setting and the large role that nonmarket benefits must play in order to offset the cost of producing output less efficiently (as is often the case when shifting from nonlocal to local production). The results also highlight the challenges associated with valuing nonmarket benefits in this setting and indicate paths forward for researchers and practitioners in this area.

\section{Measuring the Economic Impacts of Local Foods}

As discussed by O'Hara and Pirog (2013), most existing studies considering the economic impacts of local food use input-output models, such as IMPLAN. ${ }^{2}$ Input-output models provide estimates of the impacts of local food system investment on key indicators like employment and household income. ${ }^{3}$ Some recent examples include Christensen et al. (2019), Conner et al. (2017), Jablonski et al.

\footnotetext{
${ }^{1}$ Specifically, placing my setting within Winfree and Watson's framework, I assume competitive markets and remain agnostic about the motivations of both OSU Dining Services (the intermediate buyer) and OSU students.

${ }^{2}$ Computable general equilibrium (CGE) models are also sometimes used to examine economic impacts and have the distinct advantage of allowing for more flexibility than input-output models, but they are also very technically challenging to implement and thus are used less frequently.

${ }^{3}$ Input-output analysis and cost-benefit analysis are not the only two approaches to understanding the economic impacts of local food systems. Goldenberg and Meter (2019) suggest that the "black box" of input-output analysis can give numbers that are dubious and suggest instead measuring connectivity via social network analysis, which would help to show how spending may be transferred between food system stakeholders. However, without incorporating opportunity cost, it is unclear that connectivity leads necessarily
} 
(2016), and Miller et al. (2015). In addition, Bauman and Thilmany McFadden (2017) describe the evolution of economic impact analysis using inputoutput methods in local food settings.

Input-output models describe a regional economy in terms of transactions between firms (who sell outputs, earn revenue, and purchase labor and other firms' outputs) and households (who sell their labor, earn income, purchase outputs, and save for the future), as well as imports into and exports out of the region of interest. These transactions can be expressed as a series of linear equations (a matrix). The key to solving this model is that everything has to go somewhere; for example, all revenue earned by a firm must go to households (in the form of wages/income), other firms (in the form of expenditures on inputs), or other entities outside the economy (in the form of payments for imports). For example, if you increase the amount that a firm earns in revenue, more money must go to households, other firms, or the providers of imports.

Observed data about a regional economy are used to characterize and estimate the relationships between all these different stakeholders. This process then generates an input-output model that can be used to simulate the impacts of various shocks or investments within the economy; IMPLAN is an example of such a model. A user will input a change- such as a shift from nonlocal to local purchasing by a firm - and then see what happens to this investment given the relationships between firms and households in the economy. The impacts of such an investment could be changes in employment, revenue for firms, or income for households, as these are all aspects of the economy that are captured by the model. Input-output models can also be used to generate multipliers, numbers that indicate how much of the initial dollar amount invested stays in the local economy, which in turn is determined by the relationship between industries, households, and outside regions in the model.

The key strengths of the input-output method- ology of economic impact analysis are its ability to provide tangible economic indicators that are desired by decision-makers and its ability to disaggregate these impacts across stakeholders. However, without modification, standard input-output models like IMPLAN make highly simplistic assumptions that do not match most local food settings, such as that resources used for local food production were previously idle (as opposed to being used in an alternative productive activity), and that consumers do not decrease other local purchases when they increase local food consumption. ${ }^{4}$ Furthermore, while the outputs of this analysis are very useful, and it can be tempting to see input-output analysis as the only decision-making tool needed, the outputs only capture the flow of goods, services, and money in markets. They do not capture nonmarket impacts of local food systems, which are commonly among the motivations for local food system investments. In addition, as we consider the future of the food system more broadly, there is a bigger question-do local food system investments benefit society as a whole once we expand our analysis beyond the local region? While this seems like a simple enough question at first glance, "benefiting society as a whole" is vague. What does this phrase mean? How do we measure it?

Within the field of economics, these benefits are often expressed using the economic concept of welfare, another term for benefit or well-being. Individuals make choices as to what to buy by maximizing their well-being subject to constraints (time, income, etc.). Based on this optimization, consumers will have a willingness to purchase a good or service that is expressed as a function of price (commonly referred to as a demand curve). Similarly, businesses make choices as to what to sell by maximizing their profit (revenue they earn from sales minus cost of production). The functions which indicate the quantities of goods and services at each price that buyers are willing and able to buy and sellers are willing and able to sell

to more societal welfare, as this depends on what stakeholders were doing in the absence of connectivity. Nevertheless, it poses a promising and interesting tool that increases transparency.

4 Thilmany McFadden et al. (2017) provide detailed instructions for adjusting the standard model to more accurately represent local food settings. 
are referred to as demand and supply curves, respectively. In a competitive market, it is the intersection of demand and supply curves-when the quantity produced/sold is exactly equal to the quantity purchased/consumed-that determines the market price of a good or service. As individuals, we will purchase a good or service if our willingness and ability to buy (often referred to simply as willingness to pay) is higher than the price. If our willingness to pay is exactly equal to the price of a good, and we purchase that good, then we exchange money for the good of equal value and we don't gain any welfare as consumers (called consumer surplus). If we have a willingness to pay that is greater than the price, then we gain consumer surplus from this purchase because we have traded some amount of money for a good that we value at more than that amount of money. Similarly, sellers will produce and sell a good if the cost to produce that particular unit of their good or service is less than the price. If a seller's cost is exactly equal to the price of the good, and they sell that unit of the good, then all the money they earn on that sale will be used to cover the cost of producing that good, and they gain no welfare as sellers (called producer surplus). If sellers have a cost of production that is less than the price of the good, then they gain producer surplus from this sale because they have earned more from the sale than the good cost to produce. ${ }^{5}$

The goal of cost-benefit analysis is to capture these changes in welfare to understand what Watson et al. (2007) call economic benefits of an activity, program, or investment to society. Cost-benefit analysis allows for the inclusion not just of economic activities, but of impacts on society from changes in nonmarket outcomes (environmental, community, etc.). Cost-benefit analysis can also provide a transparent view of the categories of welfare impacts and demonstrate the particular benefits and costs that make up the largest components of welfare changes, providing insight about which levers are most important to pull in order to make sourcing decisions that yield the greatest benefit to society. The weaknesses of this approach are that it involves converting things into monetary terms that are felt by some should not or cannot be measured in dollars (e.g., community well-being), it does not as easily disaggregate some stakeholders, and it says nothing about the distribution of welfare across various stakeholders, which may well be of interest.

Despite these weaknesses, cost-benefit analysis is a powerful and valuable tool, and importantly, the most appropriate tool for answering a crucial question frequently asked: will this project we're pursuing benefit society? If the analysis finds that local sourcing yields a net benefit to society, it can be used by local food system advocates to better support their case for decision-makers to support local food investments. However, if the study suggests a project will yield a net loss to society, it can help redirect food system efforts to more beneficial activities. In addition, it can be useful in decisionmaking for those who wish to make decisions that benefit society as a whole while also supporting their local communities. More broadly, it can be a helpful tool for anyone trying to better understand the trade-offs of local sourcing.

\section{Institutional Setting}

Institutions, including colleges and universities, K12 schools, early childhood care and education settings, hospitals, elder care settings, corporate cafeterias, faith-based organizations, and prisons are increasingly seen as important players in local and regional food systems (Benson \& Fleury, 2017; Harris et al., 2012). Not only do they offer a more stable source of local food demand than some direct-to-consumer settings, like farmers markets and online direct sales, due to the nature of institutional food service planning, but many also have a specific interest in the health and/or nutrition education of their users, patients, or residents due to the nature of their work, and embeddedness within their communities drives interest in supporting local farmers (Conner et al., 2014; Harris et al., 2012). Indeed, a number of studies have found evidence that supply-chain stakeholders in these farm-to-institution settings are motivated by values other than

\footnotetext{
5 This topic is covered in most introductory economics textbooks; see, for example, The Economy, developed by the CORE Project, which is available free online at https://www.core-econ.org/the-economy. The topic is covered in Chapter 7.
} 
profit. However, many challenges remain, including logistical, administrative, and aggregation challenges that come from the interactions of large bureaucracies with individual local farmer vendors (Feenstra et al., 2011; Heiss et al., 2015; Matts et al., 2015). These motivations increase the importance of determining if these institutional relationships are meeting the values-oriented goals of the participating stakeholders, goals that cannot be captured in input-output models.

As a public, land-grant university, OSU is engaged in food systems through research and innovation, teaching and learning, outreach and engagement, and resource stewardship (Fox, 2017). One way that OSU has engaged in resource stewardship is by setting a goal to source $40 \%$ of food served at the university from local and sustainable sources by 2025 (OSU, 2016). To meet this goal, OSU Dining Services, which in its traditional dining hall locations alone serves approximately 11,000 meals per day to students, faculty, and staff, must find new sources for some of their products (L. Holford, personal communication, May 19, 2017).

Prior to the 2016-2017 academic year, OSU Dining Services purchased sweet potatoes from a distributor based in Ohio that sourced from another Ohio distributor. The latter distributor sourced from a sweet potato packer in North Carolina (personal communication with vendor, May 22, 2017). North Carolina produced more than half of U.S.-produced sweet potatoes in 2016, making it a likely source for major distributors based in the eastern United States (USDA NASS, 2020). (The supplier in North Carolina will be denoted the "nonlocal supplier" and the sourcing policy the "status quo policy.") In 2016, OSU Dining Services began sourcing approximately $25 \%$ of their sweet potatoes from a local, cooperatively owned supplier that aggregated from farmers and delivered di- rectly to the university, denoted the "local" supplier. Sweet potatoes produced by this supplier are not only local to OSU (all farms are less than 100 miles from OSU, and most are less than 25 miles away), but also organic. ${ }^{6,7} \mathrm{~A}$ schematic of these two supply chains is provided in Figure 1.

Once purchased by OSU, the sweet potatoes considered in this analysis are served as whole, baked sweet potatoes. Sweet potato fries, which are sourced from the same regional distributor, go through a different supply chain and are not considered in this analysis. The whole, baked sweet potatoes are offered in three Traditions dining locations on OSU's main campus in Columbus. These dining halls use an all-you-care-to-eat model. Student meal plans include a combination of meals at Traditions dining locations as well as other more liquid forms of payment that can be used at a variety of dining locations across campus (OSU, 2021a).

\section{Methods}

The method employed to answer the research question is a retrospective cost-benefit analysis of OSU Dining Service's first year of local sourcing of this product. The organization of the approach draws from the conceptual framework for costbenefit analysis outlined in Boardman et al. (2011). Incremental net benefits are reported. In other words, the analysis compares the local sourcing decision to the status quo policy of sourcing all sweet potatoes from the nonlocal supplier rather than reporting the full costs and benefits of both sourcing policies. To calculate net benefits, first the impacted stakeholders are defined. Then the welfare impacts of the change on each stakeholder group are cataloged and estimated using a combination of economic theory and data provided by OSU Dining Services and their vendors, as well as publicly available data and estimates from the literature.

These data and values are then used to param-

\footnotetext{
${ }^{6}$ The definition of local used in procurement varies considerably across institutions. The OSU Food Sustainability Panel in its fall 2018 final report defined local based on zones: ultralocal (within 50 miles of OSU serving location), Ohio-produced (produced within the state), regional (produced within 275 miles), North America (produced within the U.S., Canada, Central America, and the Caribbean), and beyond or unknown (produced outside North America or in unknown location) (OSU, 2018).

${ }^{7}$ These sourcing changes were chosen by OSU Dining Services, as was the product considered in this cost-benefit analysis. Based on conversations with Dining Services staff, I have no reason to believe this product was picked strategically to lead to a particular result of the cost-benefit analysis. Rather, local sourcing for the product was just beginning and the Dining Services team was eager to better understand the impacts of this sourcing choice.
} 
eterize a Monte Carlo simulation model. Monte Carlo simulation is a method for accounting for uncertainty of key parameters in the analysis (e.g., the maximum willingness to pay for sweet potatoes or the responsiveness of consumers to price) by simulating a large number of scenarios using a range of possible parameter values and using information about these scenarios (rather than a single

Figure 1. Local (Ohio) and Nonlocal (North Carolina) Supply Chains

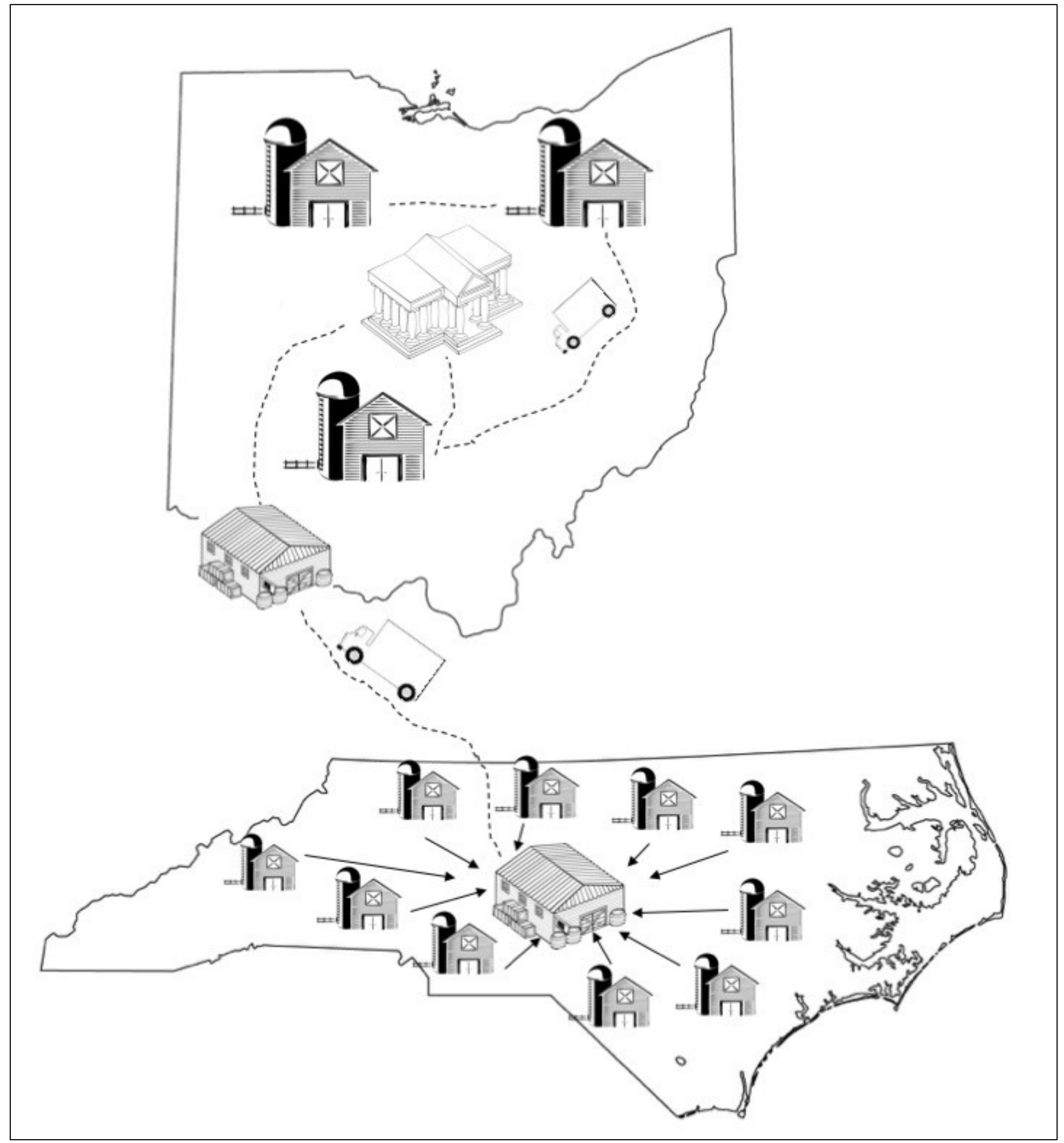

Note: Drawings are not to scale. Positions of states in the figure are not intended to represent relative positions of states geographically, and locations of farms and warehouses in the states are not intended to represent geographic locations of specific business entities. 
estimated value) to answer the research question. Because many of the parameter values in this study are drawn from other settings rather than from observational OSU data, acknowledging and accounting for this uncertainty is particularly important. To conduct the simulation, I assume a distribution for all key parameters based on literature or expert knowledge of the setting. Then I take random draws from the distribution for each of the key parameters and use them to calculate the net benefit. I then repeat the process 9,999 times, to yield 10,000 unique net benefit calculations. This procedure is conducted with the computer program Matlab. If the net benefits from the sourcing change are greater than zero, then the local sourcing policy provides a net welfare gain to society; alternatively, a negative net benefit indicates a net loss to society. With the information from the 10,000 simulations, I can examine the distribution of the net benefit estimates, given uncertainty in these key parameters. For example, I can see the share of the 10,000 scenarios that yield a net benefit greater than zero and the share of the scenarios that yield highly negative or highly positive values. As in Jeuland and Pattanayak (2012), given no prior knowledge of the distributional form of these parameters I assume a uniform distribution for all parameters I allow to vary, so that the probability of choosing any particular value within the range that I set is equal for all values within the range.

\section{Impacted Stakeholder Groups}

First, it is important to consider those individuals or groups who have standing, i.e., those stakeholders who are likely to be affected by the change. Inclusion of particular groups can be controversial in cost-benefit analysis, particularly in the case of local food investment, as the endeavor in itself emphasizes the importance of local businesses and residents relative to businesses and residents elsewhere. In economic impact analysis using inputoutput methods, the focus is on individuals and firms in a particular region, with imports and exports serving as the only connections outside the region. In contrast, because cost-benefit analysis does not involve structural modeling of the economy, it is generally more difficult to disaggregate welfare accruing to local and nonlocal firms and individuals, and it is not necessarily a goal of the analysis. Given the setting, OSU and OSU students clearly have standing, as do local residents and local farmers. If the goal is to understand the impacts of the local sourcing decision on society as a whole, actors in the nonlocal supply chain must also be given standing, as they may potentially be impacted by the sourcing change. However, this choice may be controversial. ${ }^{8}$ Another possible group with standing is the global population. While it might seem unnecessarily expansive to consider all people, it is important to consider the global population when valuing the impacts of environmental externalities from food production, processing, and transport. For example, the social cost of carbon, often used in cost-benefit analyses to value the impact of carbon emissions, is based on global costs.

\section{Impacts}

\section{University}

The university is likely to be impacted in several ways. First is the change in the cost of the product due to switching to the local supplier. Based on records provided by OSU Dining Services, the average prices per pound paid by OSU Dining Services during the 2016-2017 academic year were US $\$ 0.55$ and US $\$ 1.25$ for nonlocal sweet potatoes and local sweet potatoes, respectively (L. Holford, personal communication, March 27, 2017). The expenditure by OSU on local sweet potatoes represents one component of the opportunity cost of local sourcing; other components are discussed in the section on local farmers. In the 2016-2017 academic year, OSU Dining Services purchased 37,173 pounds of sweet potatoes. ${ }^{9}$ Of these, $9,060(24.4 \%)$

\footnotetext{
${ }^{8}$ Although not within the scope of this paper, the importance of local producers would suggest a role for distributionally weighted cost-benefit analysis, with a higher weight given to local producers. However, determining the appropriate weight to give to local producers in such an analysis would no doubt be controversial. It will become apparent later in the paper that in the case under examination, the question of standing for nonlocal producers may well be irrelevant.

${ }^{9}$ This quantity is based on data made available in March. For this analysis, April and May purchasing are assumed to be equal to the
} 
came from the local supplier (L. Holford, personal communication, March 27, 2017). Since these quantities are known values, they are not allowed to vary in the simulations.

Another impact to consider is the cost of establishing the relationship between OSU Dining Services staff and the new local vendor, as social relationships between supply-chain actors are understood to be an important aspect of farm-to-institution programs (Buckley et al., 2013). OSU Dining Services staff indicate they do not negotiate prices with suppliers, so OSU Dining Services labor costs are unlikely to be incorporated in the price paid to the new local vendor through a lower price. OSU Dining Services staff did not track their time establishing this vendor relationship separately from their other activities, so these labor costs incurred by OSU are based on data from the publicly available OSU salary database (Buchanan, 2017). It is assumed that the executive chef and receiving manager both have spent time developing this relationship. ${ }^{10}$ These staff had difficulty estimating the time involved in developing the relationship, so I assume the number of hours spent by each in the first year is uniformly distributed between 0 and 10 hours.

These employees' effective hourly wages are then calculated based on the salary information and multiplied by the unclassified staff benefit rate of $37 \%$ to get the cost to OSU per hour of work (OSU, 2021b). Beyond the cost of establishing the relationship, OSU Dining Services staff indicated no difference in receiving or preparing cost between the sweet potatoes sourced from the local and nonlocal suppliers (L. Holford, personal communication, May 19, 2017). Thus, the only cost differences for OSU Dining Services are the cost of establishing the relationship with the vendor and difference in price for the local sweet potatoes.

Although OSU Dining Services did not raise the price of the student meal plan due to these in- creased costs, the long-term effects of any increase in food costs due to additional local and sustainable sourcing could very well be an increase in the price students pay. ${ }^{11}$ If students remained on the meal plan after a plan price increase, the increase would serve simply as a transfer from students to OSU Dining Services and therefore would not affect the results of the cost-benefit analysis. However, to the extent that students no longer purchased the meal plan due to this change, the change could affect the net benefits of local sourcing. These kinds of long-term impacts are important for universities to consider.

Yet another possible consideration is the set of alternative policies facing the university. One challenge of cost-benefit analysis is how best to restrict the set of policy alternatives. Although the choice set considered in this analysis is very narrow, in fact, the set of policies could be broadened for a follow-up analysis exploring possible alternatives. Given the ample evidence of returns to education, would the money used to purchase local foods yield a greater benefit to society if employed in the form of something entirely different, like a scholarship? A wide variety of options could potentially be considered. For the purposes of this paper, it is assumed that OSU Dining Services is allocated an annual budget, and once this budget is allocated OSU Dining Services must spend that money on activities within its budgetary control, ruling out such policy alternatives.

An anonymous reviewer has noted additional benefits that could accrue to the university, including connections to alumni and enhanced university image within the community. Conceivably the university advancement office could track the importance of these benefits (at least qualitatively) through their various data collections, which may be a useful strategy moving forward for universities investing in local food systems. Producer or alumni local food donations are also a possibility, although

academic year monthly average up to that point and that June and July purchases are $25 \%$ of the monthly average for the academic year.

${ }^{10}$ The title of the executive chef in the salary database is assistant director, Residence \& Dining, Food Service.

${ }^{11}$ This is solely my prediction, based on simple economic principles and was never mentioned or suggested during conversations with OSU Dining Services staff in the course of this project. 
it should be noted that donations may not yield a net benefit. A donation of produce could benefit the university and may benefit the producer or alumnus/a through psychological impacts of altruism, but the producer is giving up the revenue that they would have received from selling this product (the opportunity cost). Thus, the distribution of welfare would change, but the net benefit is not likely to be considerably different from the scenario in which the producer sells their product to the university.

\section{Students}

Students are the consumers of the product. Some evidence suggests that students are unwilling to pay the same kinds of premiums that grocery store shoppers would pay for a local or organic product. Bruno and Campbell (2016) found that only 50\% of students they surveyed at the University of Connecticut in 2015 were willing to pay a premium for more local food options and only $50 \%$ of students were willing to pay a premium for more organic options. ${ }^{12}$ The average willingness to pay (WTP) for more local options for students with a meal plan in the study was US $\$ 17.14$, or approximately $1-2 \%$ of their meal plan cost, while the average WTP for more organic was slightly larger, at US $\$ 20.69 .13,14$ Porter et al. (2017) surveyed students at the University of Vermont and found a somewhat higher willingness to pay for a combination of these attributes relative to Bruno and Campbell (2016): 70.8\% indicated they would be willing to pay a positive premium. However, this premium was for $20 \%$ of their food to be produced locally using ecologically sound, fair, and humane practices, which differs from the attribute set consid- ered by Bruno and Campbell (2016). For those willing to pay a premium for this combination of attributes, the median premium represented a 3\% meal plan price increase, and the mean premium represented a $3.4 \%$ price increase.

As these studies are focused on large changes in sourcing and not changes in sourcing of particular products - as is the focus of this paper-it is important to consider other literature that looks at price premiums for specific relevant products. Estimates in the literature range considerably, including a local premium of 10\% (Loureiro \& Hine, 2002), 18\% (Nalley et al., 2006), 16-31\% (Darby et al., 2008) and 27\% (Carpio \& Isengildina-Massa, 2009). This evidence would suggest students may put a premium of anywhere from $1 \%$ to $31 \%$ on local sweet potatoes.

However, in order to calculate the premium students place on local sweet potatoes, it is necessary to understand students' current demand. Student demand for foods in a dining hall are particularly complex; at Traditions dining halls, students on a meal plan and other visitors pay a fixed fee to enter. ${ }^{15}$ Furthermore, Traditions locations are allyou-care-to-eat. Therefore, once inside, the additional (or marginal) cost of any specific food items, including sweet potatoes, will be zero. Consumer surplus from the consumption of sweet potatoes will be the entire area under the demand curve for sweet potatoes by Traditions diners minus the fixed cost of entry. ${ }^{16}$ Thus, to calculate the difference in the consumer surplus that students (and potentially faculty, staff, and other visitors) receive, an estimate for the demand for sweet potatoes is needed.

A stylized description of the market for sweet potatoes for OSU students is provided in Figure 2.

\footnotetext{
12 The study is not clear about whether or not these are the same $50 \%$.

${ }^{13}$ It is not clear from the article if the survey asked students about a specific quantity increase. If no specific quantity was given in the survey, uncertainty about the quantity of local food to be provided could have biased students' WTP downward, so this percentage is likely a lower bound for the premium these students would place on local food.

${ }^{14}$ Interestingly, Bruno and Campbell (2016) found that students who regularly purchased fruits and vegetables were willing to pay a smaller premium for local than other students. The authors speculated that this might be because students expected transportation costs for local foods to be lower and therefore thought local foods should be cheaper.

15 Students pay with one "visit" or anyone can pay a fixed price in either "Dining Dollars" or cash.

16 The fixed cost of entry in and of itself is rather complex. Student meal plans offer a fixed number of visits per week, and visits do not roll over to the next week. However, some meal plans allow students to exchange "visits," which can only be used in Traditions dining locations, for more flexible forms of payment that can be used elsewhere on campus and can be rolled over from week to week. A visit is worth considerably less in this more liquid form (OSU, 2021a).
} 
The demand for whole baked sweet potatoes is assumed to be linear. I assume the maximum WTP by students without the local product is uniformly distributed between one and four dollars per pound. This range is based on the maximum willingness to pay found in Nalley et al.'s (2006) experiment for sweet potatoes. The marginal cost to students for both local and nonlocal sweet potatoes is zero, as they pay a two-part tariff at the dining hall: a fixed fee equal to the meal plan per-meal price and a per-unit price equal to zero for the sweet potatoes themselves. Thus, I can approximate the total consumer surplus (before subtracting the fixed fee for Traditions visits) as the area under the demand curve before the introduction of local purchasing. I assume that student diners receive new consumer surplus from the introduction of local, which I allow to vary from $0 \%$ to $30 \%$ of the total consumer surplus from sweet potatoes in

\section{Figure 2. Stylized Demand for Sweet Potatoes by Ohio State Students}

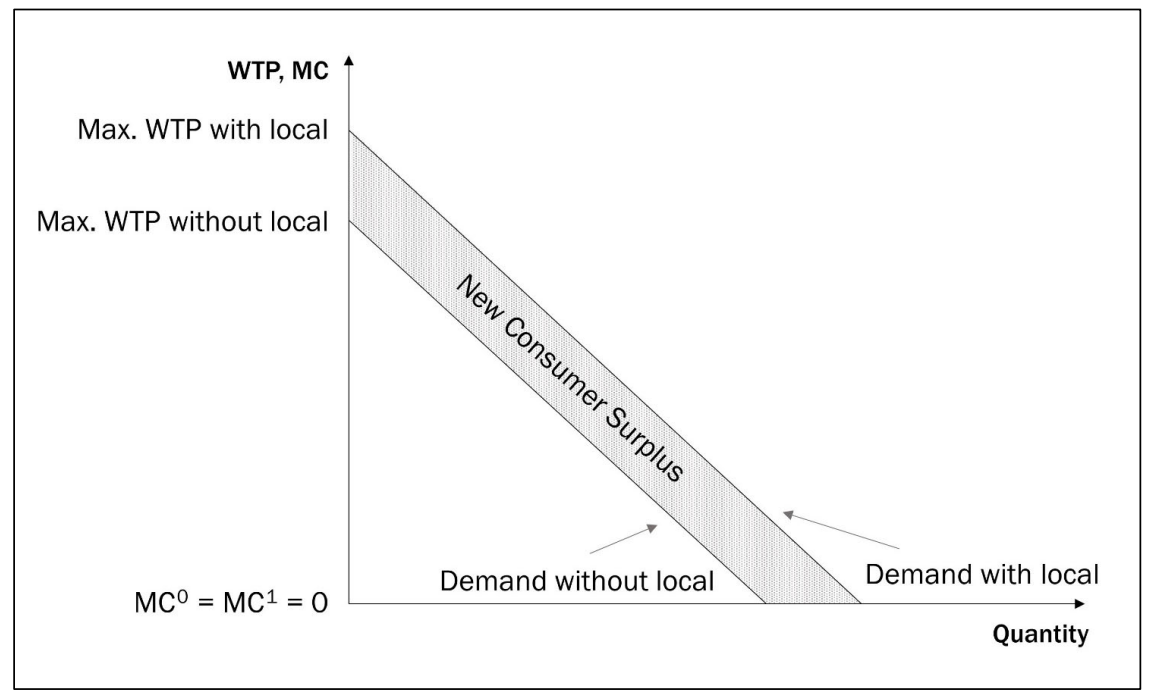

Note: MC indicates marginal cost and WTP indicates willingness to pay. the absence of local sourcing, based on the variability in estimates, described in the literature above. ${ }^{17}$ The area representing this new consumer surplus from local sourcing accruing to students is shown in Figure 2.

\section{Local Farmers and Community}

As cited in previous studies of institutional buyers of local food, lack of availability of local food both in adequate quantities and year-round can be a significant barrier to local sourcing by large institutions (see, for example, Hardesty, 2008). In the present study, in the first year of sourcing (20162017), the local supplier was able to provide from October through early March. Throughout the year the buyers at OSU Dining Services purchased from the nonlocal supplier as well. Although production numbers are unavailable from 2016 for direct comparison to North Carolina, in 2012 producers in Ohio harvested 39 acres of sweet potatoes, and in 2015 they harvested just five acres of National Organic Program-certified organic sweet potatoes (USDA NASS, 2020). Based on 2015 yield estimates (4,980 pounds/ acre), OSU's demand from local sources ( 9,060 pounds) would represent approximately two acres of production.

Given the small size of the market for local, organic sweet potatoes in Ohio, it is reasonable to assume that the market for local sweet potatoes is affected by the OSU

\footnotetext{
17 One complication for this analysis is that during the 2016-2017 academic year, sweet potatoes were not in fact labeled as local or organic in Traditions dining halls when they were purchased, which suggests that the demand by students in that academic year was actually the demand for sweet potatoes with an unknown location of origin rather than local sweet potatoes. Thus, it is not clear that the calculation of additional willingness to pay here is even appropriate if local, organic sweet potatoes are assumed to be a credence good (i.e., having attributes valued by consumers that cannot be deduced through consumption) rather than an experience good (e.g., due to freshness). The calculation used here also does not include the possibility that some students may choose to eat sweet potatoes instead of other goods if the sweet potatoes are local and/or organic. In addition, the literature provides ample evidence that localness can be confounded with other attributes consumers value, including organic certification (e.g., Hu et al., 2012 and Meas et al., 2015). If students place additional value on organic certification when products are already local, my estimate for the welfare impacts of local food could be biased downward.
} 
sourcing change. Demand for sweet potatoes in the local market will shift outward, and assuming an upward sloping supply curve for local, organic sweet potatoes (in other words, that supply is not perfectly elastic), then local producers will gain from the shift. Figure 3 presents a stylized rendering of this shift. Farmers in fact will receive two types of surplus (benefit) from this shift. The rise in price from OSU participation in the market will result in a transfer of surplus from existing (i.e., non-OSU) local consumers to local farmers, and it will allow for additional production of sweet potatoes, leading farmers to gain new surplus. The opportunity cost of producing the local, organic sweet potatoes is then OSU's expenditure minus the new surplus benefits accruing to the local producers. ${ }^{18}$ This opportunity cost is likely to be quite high, as OSU's average price paid per pound more than doubled, from US $\$ 0.55$ to US $\$ 1.25$, with the move from nonlocal to local sourcing. This increase in price is likely due to lower technical efficiency in production (i.e., fewer units of output produced given the same amounts of inputs) by Ohio sweet potato producers relative to those in North Carolina. This lower technical efficiency is generally viewed as one of the downsides of local sourcing and suggests that additional benefits must accrue to Ohioans from local production and consumption to offset this efficiency loss if a switch to local production is to increase welfare. However, as I will discuss later in the paper, the impacts of the change are not that simple, as they depend on how the particular inputs used in production in Ohio were used previously.

For the purposes of this study, it is assumed that demand for local, organic sweet potatoes is linear and that all organic production in Ohio is consumed locally (within the state of Ohio). The demand and supply functions for 2016 are assumed to be linear and are parameterized using 2016 Ohio organic production and sales data available from the USDA NASS (2020). I assume that both demand for and supply of sweet potatoes are elastic relative to nonlocal production and consumption, and both are assumed to be uniformly distributed and range in magnitude from 0 to 6 (Andreyeva et al., 2010; Okrent \& Alston, 2012b). ${ }^{19}$ Evidence in

\section{Figure 3. Stylized Market for Local, Organic Sweet Potatoes}

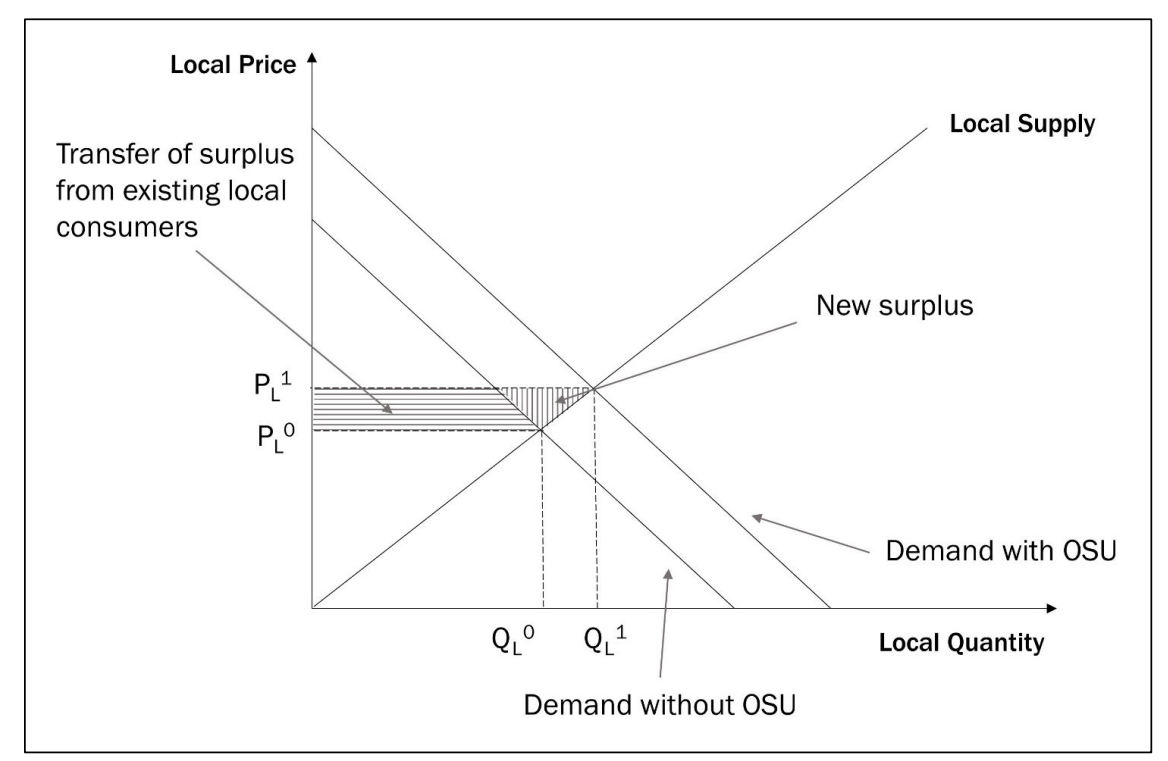

Note: PL indicates equilibrium local price, and QL indicates equilibrium local quantity.

\footnotetext{
${ }^{18}$ It should be noted that this approach to considering opportunity costs is markedly different from the way that opportunity costs are considered in many input-output models. In particular, as Thilmany McFadden et al. (2017) show, the default input-output model assumption is that all demand is new and that the resources being employed in the local food system were previously idle, so inputoutput model assumptions must be adjusted by users in order to incorporate the more realistic assumption that some local resources (e.g., land and labor) were being used in other ways prior to the increase in local spending.

${ }^{19}$ Elasticity (specifically price elasticity of demand or supply) is a measure of price sensitivity. Elastic demand or supply is signified by a number greater than one in magnitude and denotes that the quantity demanded or supplied is very sensitive to changes in price. Inelastic demand or supply denotes that the quantity demanded or supplied is not very sensitive to changes in price, and is signified by a number between zero and one in magnitude. Although price elasticity of demand is negative when calculated, I use the economic convention of reporting the magnitude of the value only.
} 
the literature suggests that demand for specific fruits and vegetables is relatively insensitive to changes in price (i.e., inelastic), although some estimates range up to 3 (with any value above 1 being elastic). Price elasticity of supply has been less researched for specialty crops than for commodity crops, but existing evidence suggests a similar range is appropriate (Okrent \& Alston, 2012a). I assume a larger range of price elasticities of demand and supply relative to the nonorganic, nonlocal market (discussed in the next section) because buyers have many close substitutes, including nonorganic local sweet potatoes and organic nonlocal sweet potatoes (in contrast, most existing studies examine one common category of goods like apples or potatoes), and sellers are substantially diversified and thus are likely to able to switch relatively easily between crops. The assumption of elastic supply is also supported by the observation that 2016 production of sweet potatoes in Ohio represented an increase in production over 2015 that was approximately the size of the quantity purchased by OSU in 2016, suggesting that this demand represented all new demand for producers. However, it should be noted that when supply is highly elastic, new demand will not cause a change in price, and local farmers will gain no additional surplus.

Whenever there is an increase in local demand, farmers will be using additional inputs. The use of these inputs is included in the opportunity cost of purchasing this product. Any additional surplus in input markets is not captured as a benefit in this cost-benefit analysis. It is possible that the new demand will yield indirect impacts in input markets if the inputs were previously idle. However, by assuming that the cost of production for local farmers is the opportunity cost of using these inputs, although production is now local and entirely new, there are in fact no gains to the local economy beyond local farmers' new producer surplus.

It is unclear whether or not it makes sense to incorporate the cost of establishing the relationship with OSU as a separate category. For the local producer, it would seem reasonable to include labor costs associated with establishing the relationship in the cost of production, so this cost is not considered explicitly, in contrast to the university. Fur- thermore, the distributor is a cooperative in this particular case, so the entirety of the price paid by OSU Dining Services is assumed to go to producers (in contrast to the nonlocal case, as described in the next section).

Finally, it may be important to consider the additional nonmarket benefits that local farmers may receive from selling to OSU. For example, Conner et al. (2012) conducted a cluster analysis based on a survey of Vermont farmers engaged in farm-toschool sales to better understand the different characteristics of these farmers. One cluster (of three they identified) consisted of farmers who were primarily motivated by profits, and another included farmers with strong social motivations. This and other studies suggest a question, how much more satisfying is it to be a farmer producing for local markets than to engage in some other kind of work? While broad concepts such as job satisfaction might be difficult to monetize, there is no conceptual reason they could not be included in a cost-benefit analysis. Although they are not included here due to data constraints, these benefits could conceivably be estimated by measuring the pay cut individuals would be willing to take to in order to be farmers who produce for local markets, relative to other jobs they could hold. This number should be a good estimate of the lower bound of the value to them of being local food producers, as it represents the tradeoff they make between a monetary reward and the intangible benefits of being a local farmer.

\section{Nonlocal Farmers, Distributors, and Community} Some may debate whether it makes sense to include nonlocal growers in this analysis. Although estimates of welfare changes based on 2016 sales are likely to be very small, our desire to consider total societal welfare and not just local societal welfare necessitates their inclusion in the model, and a number of other studies emphasize the importance of measuring the net impacts of local food system investment, requiring its impacts outside the local food system itself (Miller \& Mann, 2020).

Assuming a yield of 19,000 pounds of sweet potatoes per acre, the average yield for North Carolina producers in 2015, it would take 1.97 acres to grow OSU Dining Services' total annual supply of 
whole sweet potatoes; this acreage represents $0.002 \%$ of the total acreage of sweet potatoes harvested in North Carolina in 2016, which was 86,000 acres (USDA NASS, 2020). ${ }^{20}$ Due to this very small share of production, prices for sweet potatoes in North Carolina are unlikely to be affected by the small decrease in demand represented by OSU's sourcing change. The process to confirm this hypothesis and calculate the magnitude of this impact is the same used to calculate the impact on local farmers. Demand is assumed to be linear, and it is parameterized using 2016 prices and quantities from USDA NASS (2020). Following the literature discussed in the previous section (Andreyeva et al., 2010; Okrent \&and Alston, 2012a 2012b), elasticities of demand and supply are assumed to be uniformly distributed between 0 and 3 in magnitude. This parameter range differs from that for the local market. While it can reasonably be assumed that there are many close substitutes for local, organic sweet potatoes and thus that demand would be relatively responsive to price, demand for North Carolina sweet potatoes is unlikely to be as responsive due to its important national role as a sweet potato supplier. Supply is also likely to be less responsive to changes in price given the specialization of producers in sweet potato production in this region. This also means that North Carolina consumers of sweet potatoes are unlikely to be affected by the change, as they will see little to no change in the price of sweet potatoes. ${ }^{21}$ For this reason, they are not currently included in this analysis. ${ }^{22}$ However, in the case of a more substantial decrease in de- mand by nonlocal buyers like OSU that did affect the equilibrium price in the North Carolina market, the price of local sweet potatoes for North Carolina consumers would decrease, making them better off.

One interesting aspect of the supply chain for the nonlocal sweet potatoes is that two of the three intermediaries between the farm and OSU are located in Ohio. It is assumed that the supply of marketing and distribution services is completely elastic. Thus, when the quantity of product they are distributing is affected due to the change in demand, the distributors' surplus is not affected. This is an assumption which it may well make sense to relax in some situations. In addition, if people in both North Carolina and Ohio are given standing, the fact that the distributors that distribute North Carolina produce are located in Ohio does not matter. However, I could consider a scenario in which local people and farms are given greater weight in a cost-benefit analysis. In this case, it would be important to consider that the two distributors between the packer and OSU are both based in Ohio. The role of local distributors in supplying nonlocal goods is an important area for future study, given their importance in supply chains.

\section{Local and Global Community}

The local and global communities are likely to be impacted in a number of ways. The local community may value the direct investment in local agriculture in ways beyond the investment itself. If this is the case, this additional utility consumers gain

\footnotetext{
${ }^{20}$ It should be noted that in 2015, producers of sweet potatoes in North Carolina were able to produce nearly four times as many pounds of sweet potatoes per acre as producers of organic-certified sweet potatoes in Ohio.

${ }^{21}$ An anonymous reviewer suggested the analysis is incomplete without accounting for this change in demand. Due to the challenges of measuring North Carolina consumption of North Carolina sweet potatoes (since, unlike Ohio, much of North Carolina sweet potato production is exported out of the state), it is more difficult to estimate this effect than it is for Ohio producers. However, my hypothesis that this effect is small is confirmed by the simulation analysis; the price of sweet potatoes in North Carolina is affected by only fractions of a cent by Ohio's sourcing change in all of my simulations, which suggests North Carolina consumers would be affected minimally, if at all.

22 As one reviewer pointed out, consumers in North Carolina could be affected by even this small relative change in demand by OSU if these consumers don't simply care about consuming local products but rather, or in addition, care about local production regardless of who consumes it-for example, as an aspect of maintaining local agricultural livelihoods. While this may be the thinking of some residents in Ohio and North Carolina, it is not really a relevant point for this current paper, since the question at hand is about how local consumption shapes welfare. If consumers care only about local production, as long as something is planted in the fields in each state and farmers earn the same or more from this product than they would from sweet potatoes, then what is planted and who buys it does not really matter. Welfare for residents of Ohio and North Carolina who care about local production will not change when an Ohio institution starts sourcing a product from Ohio for local consumption.
} 
from purchasing locally would be an additional nonmarket benefit. There are two main types of impacts that may accrue to the local and global communities that we may want to consider: environmental and social.

First, I will consider environmental benefits. There is a perception that local food systems can increase ecological resilience (Brekken et al., 2018), but positive net environmental benefits from the re-localization of food systems are not a foregone conclusion. For example, Brodt et al. (2013) conducted a life-cycle analysis (LCA) to compare environmental impacts of processing tomato production and distribution between regional (Michigan) and national (California) supply chains. They found similar energy use and emissions across the two crops when shipping to consumers in Michigan; higher energy use and greenhouse gas (GHG) emissions from transportation of California production are nearly offset by increased yields and lower GHG emissions from the production relative to production in Michigan. Similarly, Christensen et al. (2018) conducted an LCA of community supported agriculture (CSA) operations in California's Central Valley, finding considerable heterogeneity in GHG emissions across farmers of similar scale producing similar products for similar markets. For example, the source of electricity and the production efficiency of soil amendments (e.g., compost) can cause significant differences in GHG emissions across operations. Edwards-Jones (2010) provides examples of various products, some with lower environmental impacts when purchased locally and some not. Keyes et al. (2015) highlight the importance of an energy mix for storage purposes, comparing local and nonlocal apples in Nova Scotia.

A very important point to note is that it takes less land (and associated resources expended, like water or labor, per unit of land) to produce sweet potatoes in North Carolina than it does in Ohio. About two acres of land is needed to grow the 9,060 lbs. of organic sweet potatoes demanded from local sources by OSU; a similar quantity of sweet potatoes grown conventionally (i.e., nonorganically) in North Carolina could be grown on less than one-half acre of land. Thus, any environmen- tal impacts occurring on Ohio land due to the shift will likely be larger than any North Carolina environmental impacts, as the changes will apply to a larger land area.

To estimate the environmental impacts due to any production changes caused by the sourcing change, I would first need to estimate the cost of the environmental impact from production of each crop in each setting. Local environmental impacts could include changes in local water or air quality, and global environmental impacts could include changes in GHG emissions. Whether there are positive, negative, or zero environmental impacts depends on whether producers change their production in Ohio and/or North Carolina due to the OSU purchases. In both regions, there are several alternative activities to growing sweet potatoes that producers could engage in. An extreme, very unlikely case would be that producers do not produce or transport anything and that all resources sit idle. In this scenario, the environmental impacts of the change (from growing nothing to growing organic sweet potatoes) would in fact be negative, as even organic production and transportation over relatively short distances is likely to have a negative environmental impact compared to doing nothing. A more likely scenario is that farms would produce a different crop on the land and market it through their usual marketing channels. There could be either a positive or negative environmental impact. If growing sweet potatoes using the particular production practices of the farm causes less environmental impact than the alternative crop, growing sweet potatoes would yield a positive benefit. Conversely, if growing sweet potatoes with the particular production practices causes more impact than the alternative, growing sweet potatoes would yield a negative benefit. Thus, an interesting aspect of this research is understanding that the potential environmental benefits from a small sourcing change come not from production differences relative to the alternative production region, but, rather, production changes relative to the alternatives within production regions. For example, if an Ohio producer had been growing a conventional corn or soybean crop previously, and marketing it globally, then producing an organic crop and marketing it locally might be environmentally beneficial, and 
therefore contributing positively to the net benefits to society.

These environmental impacts, although conceptually easy to include in a cost-benefit analysis, are constrained by the availability of relevant data. While certain easily captured measurements of environmental impacts like "food miles" (the distance food travels from farm to consumer) were once popular, it has become widely understood that more comprehensive and holistic measures of the environmental impacts of food production are much more accurate. Life-cycle assessment (LCA) is one such methodology. ${ }^{23}$ Several recent studies have used it to explore the global warming potential, acidification potential, and eutrophication potential of corn and soybean production at the county level in the U.S. Midwest (Lee et al., 2020; Romeiko et al., 2020). ${ }^{24}$ (If cropland to produce sweet potatoes in Ohio were diverted from any crops, it would most likely be these, as $76 \%$ of Ohio's 10,960,704 acres of cropland were planted with one of the two in 2017 [USDA NASS, 2020]). However, there are several barriers to including these numbers in a cost-benefit analysis. First, economists do not appear to have estimated a dollar value for acidification and eutrophication potential, and it is not clear that the dollar values associated with each of these metrics would be uniform across space (in addition to the LCA potentials themselves varying across space). Second, when considering the monetization of global warming potential, economists suggest that it is not appropriate to consider all greenhouses gasses together, as they remain in the atmosphere for different lengths of time and impose different costs on society. Third, fewer LCA estimates exist for specialty crops than for commodity crops. I found only one LCA estimate for sweet potatoes in Ohio, and it only includes global warming potential (Uzunogullari, 2018). Finally, there is a lack of clear understanding about the LCA differences be- tween organic and conventional production systems (Meier et al., 2015). Similar information for North Carolina would also be needed for a complete analysis. More research is needed on these topics to be able to accurately and comprehensively quantify the potential environmental impacts from a sourcing change like the one I examine.

Assessing the social impacts of this sourcing change, again there is a lack of relevant data. Researchers in a variety of disciplines, including sociology, anthropology, geography, and economics, have suggested that local food systems have the potential to increase justice, social equity, democracy, food sovereignty, food equity and justice, quality of life, social capital, promoting a sense of community, making a place for community, institutionbased trust, trust in food information, structural change, community transformation, bridging diverse communities, community cohesion, transformative learning, social integration, natural human capital, and knowledge about alternative sources of food (Allen, 2010; Block et al., 2012; Boys \& Hughes, 2013; Brown \& Miller, 2008; Chen et al. 2019; Connelly et al., 2011; Franklin et al., 2011; Kerton \& Sinclair, 2010; Lutz \& Schachinger, 2013; Macias, 2008; Meehan et al., 2008). However, there is very little research that seeks to quantify and monetize these impacts. The bias toward quantifiable metrics can lead these possible impacts to be left out of analysis, while in contrast some research uses these qualitative impacts as the entire basis for a project without considering crucial quantitative information. Ideally, a cost-benefit analysis could help us understand if the community and environmental benefits are large enough to outweigh the decreased efficiencies of production. Quantification and monetization of community impacts are not included in this analysis for lack of data but remain a significant gap in the literature and an important area for future study.

\footnotetext{
${ }^{23}$ Life-cycle assessment (also called life-cycle analysis) is a set of resources and methods to measure and describe the environmental impacts of a product through its entire life cycle, from production to disposal (Sieverding et al., 2020)

${ }^{24}$ Global warming potential refers to the release of greenhouse gasses that trap the earth's heat and is usually measured in units of $\mathrm{CO}_{2}$ equivalent. Acidification potential refers to the release of pollutants into the atmosphere that can cause acid rain and is usually measured in units of $\mathrm{SO}_{2}$ equivalent. Eutrophication potential refers to the release of chemicals into surface water and is usually measured as the ratio of nitrogen and phosphorus in the average composition of algae. All three can have negative impacts on a variety of ecosystems (Socolof et al., 2001).
} 
Table 1. Known Values for Simulation (from Observed Data) (All Currencies in US\$)

\begin{tabular}{lc}
\hline Description of value & Value \\
\hline Total quantity of sweet potatoes purchased by OSU in 2016-2017 (Ibs./year, projected) & $37,173.13$ \\
\hline Quantity of sweet potatoes purchased locally in 2016-2017 (Ibs.) & 9060 \\
\hline Quantity of local, organic sweet potatoes produced in Ohio in 2016 (Ibs.) & 34,300 \\
\hline Quantity of sweet potatoes produced in North Carolina in 2016 (Ibs.) & $17,100,000$ \\
\hline Average price paid by OSU for local, organic sweet potatoes in 2016-2017 (\$/lb.) & $\$ 1.25$ \\
\hline Average farm price of organic sweet potatoes produced in Ohio in 2016 (\$/lb.) & $\$ 1.46$ \\
\hline Average price paid by OSU for nonlocal sweet potatoes in 2016-2017 (\$/lb.) & $\$ 0.55$ \\
\hline Average farm price of sweet potatoes produced in North Carolina in 2016 (\$/lb.) & $\$ 0.18$ \\
\hline Wage (including benefits) of OSU executive chef in 2016 (\$/hr.) & $\$ 57.03$ \\
\hline Wage (including benefits) of OSU receiving manager in 2016 $(\$ / \mathrm{hr})$. & $\$ 37.33$ \\
\hline
\end{tabular}

Table 2. Parameter Ranges for Simulation (from Literature) (All Values in US\$)

\begin{tabular}{lcc}
\hline & Parameter range \\
\cline { 2 - 3 } Description of parameter & Min. & Max. \\
\hline Elasticity of demand, or responsiveness of consumers to changes in price: & 0 & 6 \\
$\quad$ For organic Ohio sweet potatoes & 0 & 3 \\
$\quad$ For North Carolina sweet potatoes & 0 & 6 \\
\hline Elasticity of supply, or responsiveness of producers to changes in price: & 3 \\
$\quad$ For organic Ohio sweet potatoes & $\$ 1$ \\
\hline For North Carolina sweet potatoes & $\$ 4$ \\
\hline Student maximum willingness to pay for prepared whole sweet potatoes (\$/lb.) & 0 \\
\hline Time spent by executive chef establishing relationship (hrs./year) & 0.30 \\
\hline Time spent by receiving manager establishing relationship (hrs./year) & 10 \\
\hline
\end{tabular}

\section{Simulation Description and Results}

Tables 1 and 2 include the values and ranges of parameters, respectively, described in the sections on impacts and included in the Monte Carlo simulations. The purpose of these simulations is to measure the net benefits of local sourcing while accounting for uncertainty in the key parameters discussed throughout previous sections. Briefly, the benefits and costs included can be summarized as follows. OSU spends additional money to purchase local sweet potatoes and builds a relationship with the local vendor to do so. This provides consumer surplus benefits to students who value local produce. In addition, a small benefit (in the form of increased producer surplus) is created for local producers. Some of the new demand from OSU replaces previous purchases made by local non-OSU consumers (shown in Figure 3), but some of it does not replace others' sweet potato purchases. Given the very small amount of production this demand represents relative to the North Carolina market, that market is relatively unaffected by the decrease in demand (and it is assumed for simplicity that distributors are not affected either). Discounting, or the fact that benefits and costs now matter more to us than benefits and costs later, is not considered. Due to the short timeline and the even distribution of costs and benefits throughout 
the year, discounting is unlikely to have a substantial impact on the results. ${ }^{25}$

Figures 4, 5, and 6 display the key results. These figures present cumulative distribution functions (CDFs). Because I ran 10,000 different scenarios, or simulations, there are 10,000 different versions of each result; so rather than display a single number, these figures show the share of the 10,000 simulations (on the vertical axis) with a value at or below the value on the horizontal axis. Figure 4 shows the net benefits of OSU's sourcing change to society, considering all impacts discussed above. The net benefit estimates range from -US $\$ 6,888$ to US $\$ 22,719$ in the first year, with a median value of $-U S \$ 265$ and a mean value of US $\$ 611$. As the median suggests, in the majority of cases (out of 10,000), the net benefit is negative: local sourcing yields a net loss in societal welfare. This result can be seen in Figure 4: the CDF crosses the dashed line (marking zero net benefit) at just above 0.5 on the vertical axis, signifying that over $50 \%$ of the scenarios yield a negative net benefit. However, it should be noted that possible environmental and social benefits are not included. Estimated producer surplus accruing to Ohio producers (Figure 5) is positive, as expected, but small. The units on the horizontal axis are large because there are a small number of scenarios in which the benefits to producers are very large. Consumer surplus accruing to Ohio students is non-negative (by construction) and ranges considerably depending on the assumptions about the existing

\section{Figure 4. Annual Net Benefits of Local Sourcing Relative to Status Quo}

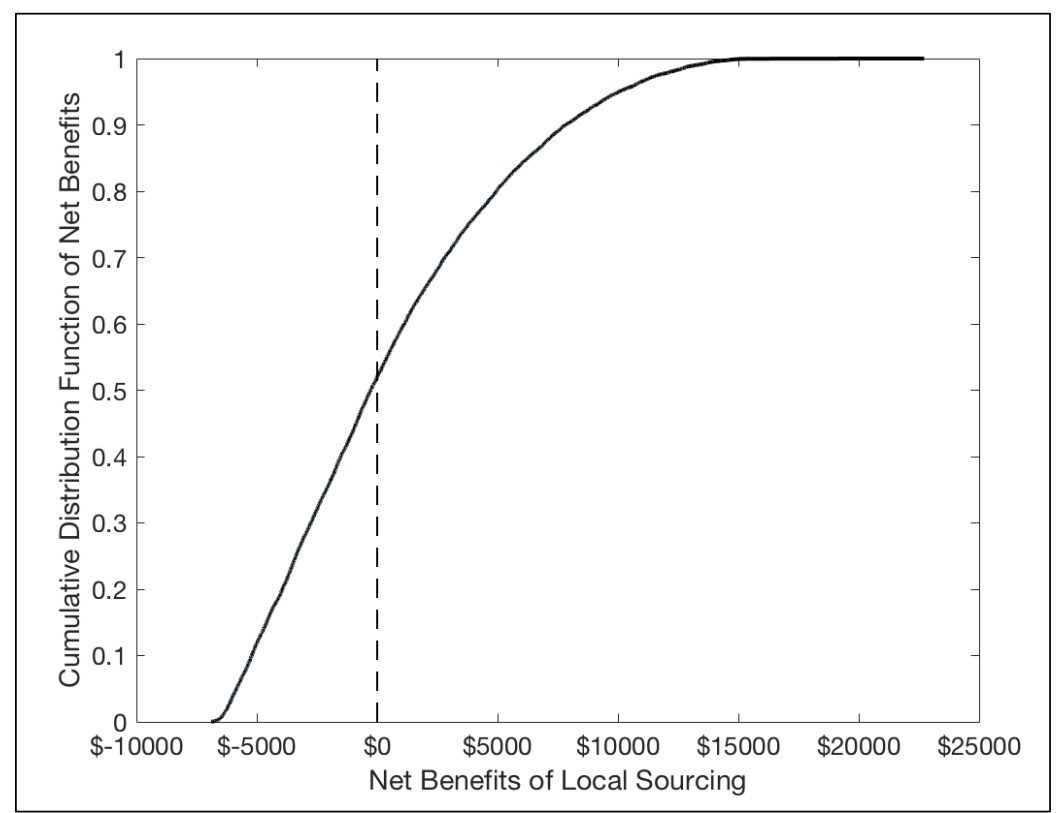

${ }^{25}$ A technical issue is the possibility of double-counting consumer or producer surplus in markets for goods that are substitutes or complements to sweet potatoes. In this case, the primary market I am using for measurement is the market for organic Ohio sweet potatoes, and the secondary market is the market for North Carolina sweet potatoes, as Ohio sweet potatoes serve as a substitute for North Carolina sweet potatoes. When observed market demand is used in analysis, changes in the market in North Carolina will be captured in the primary market (as some existing buyers of Ohio sweet potatoes choose to purchase North Carolina sweet potatoes due to the relatively cheaper prices). However, in this case I must measure the surplus in the North Carolina market, because I assume the quantity shift in demand from OSU's purchase to be exactly equal to the change in demand in the market for Ohio sweet potatoes, all else held equal. If I instead observed the change in demand in the market for Ohio sweet potatoes, part of this increase in demand by OSU would be reduced as existing consumers in Ohio shifted their demand to North Carolina sweet potatoes (with a similar effect occurring for North Carolina consumers in their local market). 
Figure 5. Producer Surplus Accruing to Ohio Producers Relative to Status Quo

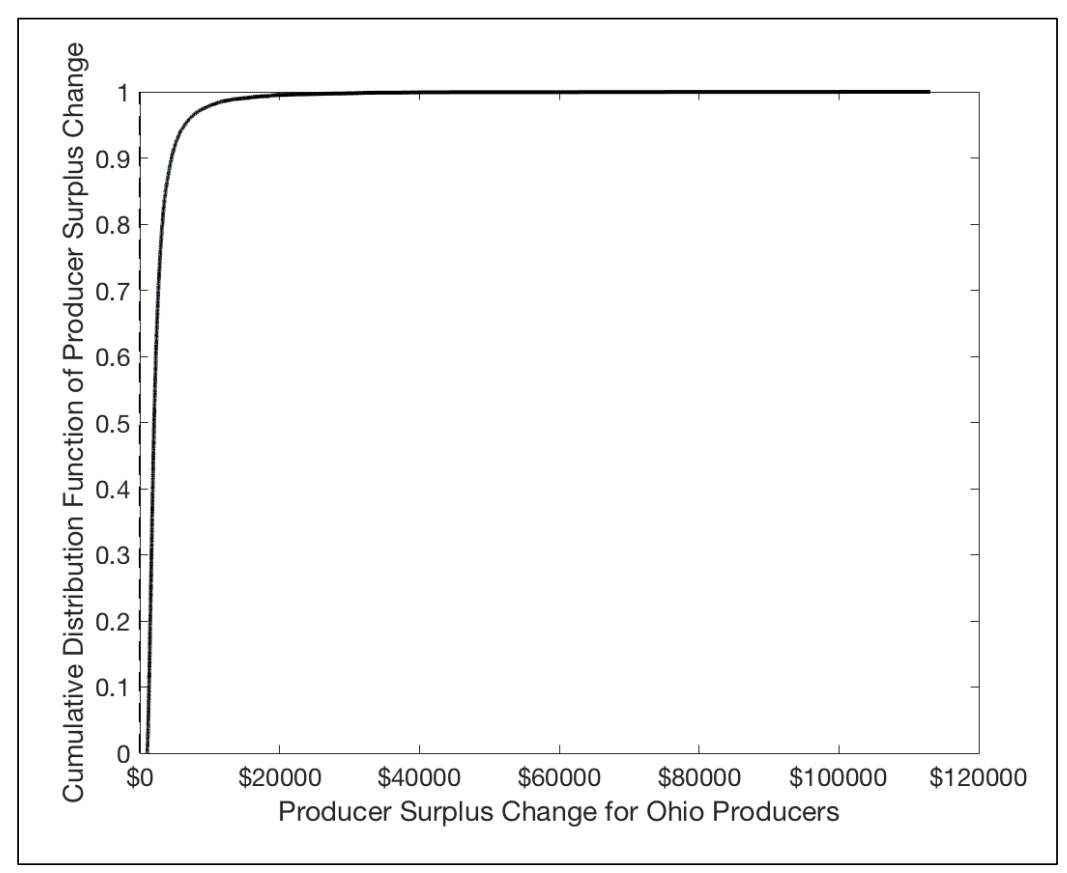

Figure 6. Consumer Surplus Accruing to Ohio State Students Relative to Status Quo

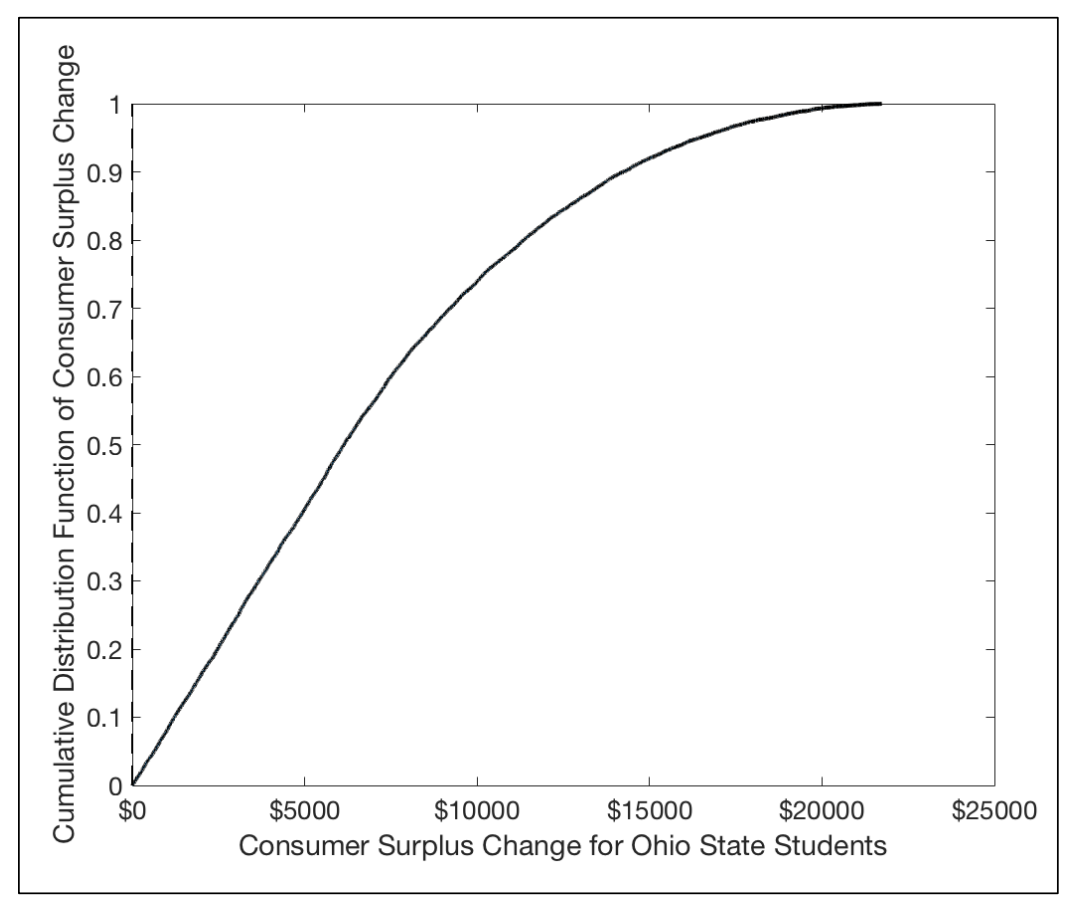

food system stakeholders want to answer the question: should we do this project? Given the costs and benefits of cost-benefit analysis itself, there are several possible paths forward for those who wish to undertake cost-benefit analysis of projects within a university setting.

Option 1: Engage faculty and students in departments with relevant expertise to conduct a complete quantitative costbenefit analysis

In order to understand the impacts of local food system investments on more than just financial flows, as provided in economic impact analyses, it is necessary to use a multidisciplinary approach. Thus the work in the present analysis comes from a wide variety of fields. As is also probably evident from this study, some of the impacts may be surprising and may not fit our common narratives. Fortunately, universities have at their disposal a wide range of experts across fields to measure these kinds of impacts. The university could create a wish list of various projects and reach out to the departments capable of undertaking these projects with the help of students and faculty and incentivize research by providing funding. ${ }^{26}$ More in-depth analyses (publishable in prestigious, peer-reviewed journals) could involve life-cycle analyses looking at local food production of various kinds to understand the environmental impacts of switching production among various crops or production practices. They could also include economic analyses such as choice experiments or con-

\footnotetext{
${ }^{26}$ In fact, this study originated with a class project I assigned in an upper-level undergraduate cost-benefit analysis class. Students' initial analyses piqued my interest and led me to conduct a more thorough exploration after the semester ended.
} 
tingent valuation studies to understand students' willingness to pay for local food products. Community impacts are more difficult to assess quantitatively, but a project on this topic could be undertaken by economists and sociologists together, breaking new ground.

Option 2: Supplement a quantitative cost-benefit analysis with qualitative information

Many of the tasks that were utilized in this paper can be conducted qualitatively through the following methods: in-depth interviews with potential vendors to understand the environmental and market impacts of their production; assessment of students' levels of interest in eating local foods, which may vary across different university settings; and discussion with current vendors about where food comes from and how it is produced. It may be that food is produced more sustainably or with more positive community impacts elsewhere than is currently known, but the length of the supply chain obscures this information. For an analysis of the food system in the local community, understanding the production and demand for food in the local food system prior to purchasing will allow the university to better understand the potential community impacts of their purchases. For example, if the university started purchasing all of a certain product from the local community, what percentage of local production of that crop would the university's purchase represent? Who would produce it? This type of interview-based, qualitative cost-benefit analysis can get the university a long way toward understanding the potential welfare impacts of its food purchases. Engaging in local purchasing relationships without an examination of these questions could lead to outcomes that are actually worse for society. In contrast, a close examination of these topics, even if performed qualitatively, could allow the university to make strategic decisions in its local food sourcing that yield the greatest potential for positive net benefits. It should be noted that existing assessment tools (e.g., from organizations like Real Food Challenge) can be useful in helping to increase transparency of university sourcing; the processes they suggest can yield data relevant to a cost-benefit analysis (although it is important to recognize the assumptions implicit in any such tool).

Option 3: Use a combination of options 1 and 2 and benefit transfer methods

The analysis in this paper heavily relies on the method of benefit transfer, the process of using existing estimates from other settings and translating them to the setting at hand. This is not an ideal approach but can give a good estimate of the range of welfare impacts, especially combined with simulation methods, like the Monte Carlo analysis used in this paper, that account for sources of uncertainty in parameter estimates.

\section{Policy Implications and Suggestions for Future Research}

This work has important implications for food policy. Considerable confidence has been placed in local food system investments as an effective tool to combat a wide variety of societal ills. Nevertheless, and surprisingly, applied welfare analysis in the form of cost-benefit analysis has not been used to examine these investments and the policies that support them. Cost-benefit analysis is a well-accepted method for evaluating policies before and after implementation to answer a question that is, hopefully, central to the work of most policymakers: does this policy make society better off? In this work I use a case study to demonstrate that the answer to this question is not unequivocally "yes" for the case of local sourcing of sweet potatoes by Ohio State University, and to set an example for how this type of analysis could be used to inform decisions by policymakers and other food system stakeholders in addition to or in place of other forms of policy evaluation. This work also highlights some important areas for continued research in the field of applied economics and other fields that could enhance the accuracy of this tool and make the required data more accessible to a variety of stakeholders.

First, while scholars outside economics have spent ample time considering the social impacts of local and regional food systems, economists have done less on this front. The relative lack of work among economists is not necessarily due to a lack of interest in understanding these impacts, but be- 
cause economists have not developed as many tools for this work as scholars in some other fields. However, these tools are far from difficult to envision. While monetizing community impacts will likely be seen as inappropriate by some, particularly non-economists, I would argue the issue of how to value social impacts is akin to the issue of how and whether to value nonmarket environmental impacts, which is increasingly accepted and expected in cost-benefit analyses. If decisionmakers continue to use cost-benefit analysis as a tool, then the value of these impacts should be considered in the setting described in this case study and in many others as well. In the current setting, it is expected that the unmeasured social benefits are positive, making the estimates in this study biased downward relative to the true net benefits of the sourcing change.

Second, this work reveals the challenges of understanding the net benefits of the environmental impacts of local sourcing, and the ways that this varies across crops and across regions. The research process undertaken here also reiterates the point made by others that the costs and benefits of local sourcing are very likely to be both crop- and location-specific. Both measuring and monetizing relevant environmental impacts will take a multidisciplinary approach that engages biological and environmental scientists, engineers, and others-to estimate the environmental impacts themselvesand economists to estimate the costs to society of those impacts for a wide variety of crops, production methods, and geographies. In general, existing estimates appear to have been generated as one-off projects and do not provide a comprehensive analysis that can be used by a variety of stakeholders. This work also conveys the importance of understanding the environmental impacts relative to previous uses of local resources rather than relative to nonlocal environmental impacts when conducting applied welfare analysis. In this setting, the expected direction of bias in my estimates is ambiguous, given the lack of information about the environmental impacts of resource use prior to sweet potato production for OSU.

In addition to these major categories of research that are important for providing accurate cost-benefit analyses of local food system investments, this work suggests a variety of important ar- eas for future quantitative research that would be valuable in similar cost-benefit analyses. Examples include student willingness to pay for products in all-you-care-to-eat dining hall settings (similar to buffets); possible nonmarket benefits to the university, such as community goodwill; responsiveness of output supply to changes in price for specialty crops; trade-offs between university dining services budgets and other services provided by the university; the long-term impacts on students stemming from sourcing changes for university meal plan prices; and the psychological and lifestyle benefits that producers get from producing for and selling to local markets.

While this work suggests that cost-benefit analysis remains somewhat inaccessible as a project evaluation tool for local food system stakeholders at present, it also demonstrates the important potential role of cost-benefit analysis as an addition to local food system stakeholders' project evaluation toolkits. Cost-benefit analysis can answer different questions than economic impact analysis does and has an important role in demonstrating net benefits and highlighting key trade-offs of local food system investments. The suggestions for future research, if acted upon, can help pave the way for increased use of this tool by local food system stakeholders moving forward.

\section{Acknowledgments}

I would like to thank Zia Ahmed and Lesa Holford of OSU Dining Services, and OSU's 2016 sweet potato vendors, for sharing information about their businesses. I would also like to acknowledge students in the Spring 2017 class of AEDECON 5330: Benefit-Cost Analysis, who worked on group projects related to this topic and planted the seed for this paper with their thoughtful presentations. The students are Douglas Alt, Mihir Baxi, Megan Fuerst, Matthew Griffin, Ann Hopkins, Wanyu Huang, Nathan Jacoby, Peter Kraner, Dan Liu, Michael Marino, Michaela Master, Michael Schaal, Andrew Shea, Audrey Stallworth, and Jessica Wheeler. I would also like to thank Brian Roe, Jill Fitzsimmons, Jane Kolodinsky, and editors and anonymous reviewers at several journals, particularly JAFSCD, for their insightful comments and support, which have surely made this work better. 


\section{References}

Allen, P. (2010). Realizing justice in local food systems. Cambridge Journal of Regions, Economy and Society, 3(2), 295-308. https://doi.org/10.1093/cjres/rsq015

Andreyeva, T., Long, M. W., \& Brownell, K. D. (2010). The impact of food prices on consumption: A systematic review of research on the price elasticity of demand for food. American Journal of Public Health, 100(2), 216-222. https://doi.org/10.2105/AJPH.2008.151415

Bauman, A., \& Thilmany McFadden, D. (2017). Exploring localized economic dynamics: Methods-driven case studies of transformation and growth in agricultural and food markets. Economic Development Quarterly, 31(3), $244-254$. https://doi.org/10.1177/0891242417709530

Benson, M., \& Fleury, D. (2017). Institutions: An emerging market for local and regional foods. In A. Dumont, D. Davis, J. Wascalus, T. C. Wilson, J. Barham, \& D. Tropp (Eds.), Harvesting opportunity: The power of regional food system investments to transform communities (pp. 189-207). Federal Reserve Bank of St. Louis. https://www.stlouisfed.org/community-development/publications/harvesting-opportunity

Block, D. R., Chávez, N., Allen, E., \& Ramirez, D. (2012). Food sovereignty, urban food access, and food activism: Contemplating the connections through examples from Chicago. Agriculture and Human Values, 29(2), $203-215$. https://doi.org/10.1007/s10460-011-9336-8

Boardman, A. E., Greenberg, D. H., Vining, A. R., \& Weimer, D. L. (2011). Cost-benefit analysis: Concepts and practice (4th ed.). Prentice Hall.

Boys, K. A., \& Hughes, D. W. (2013). A regional economics-based research agenda for local food systems. Journal of Agriculture, Food Systems, and Community Development, 3(4), 145-150. https://doi.org/10.5304/jafscd.2013.034.012

Brekken, C. A., Fiegener, R., \& Duncan, S. (2018). Linking regional food networks to ecological resilience. Choices, 33(2), 1-10. https://www.choicesmagazine.org/choices-magazine/theme-articles/the-linkages-between-entrepreneurshipand-sustainable-regional-food-networks/linking-regional-food-networks-to-ecological-resilience

Brodt, S., Kramer, K. J., Kendall, A., \& Feenstra, G. (2013). Comparing environmental impacts of regional and nationalscale food supply chains: A case study of processed tomatoes. Food Policy, 42, 106-114. https://doi.org/10.1016/i.foodpol.2013.07.004

Brown, C., \& Miller, S. (2008). The impacts of local markets: A review of research on farmers markets and community supported agriculture (CSA). American Journal of Agricultural Economics, 90(5), 1298-1302. https://doi.org/10.1111/j.1467-8276.2008.01220.x

Bruno, C. C., \& Campbell, B. L. (2016). Students' willingness to pay for more local, organic, non-GMO and general food options. Journal of Food Distribution Research, 47(3), 32-48. https://doi.org/10.22004/ag.econ.249998

Buchanan, D. (2017, April 14). Ohio State salary database for year-end 2016 through 2013. Columbus Business First. http://www.bizjournals.com/columbus/blog/2016/03/osu-salary-database-updated-for-2016-plus-the.html

Buckley, J., Conner, D. S., Matts, C., \& Hamm, M. W. (2013). Social relationships and farm-to-institution initiatives: Complexity and scale in local food systems. Journal of Hunger \& Environmental Nutrition, 8(4), 397-412. https://doi.org/10.1080/19320248.2013.816988

Carpio, C. E., \& Isengildina-Massa, O. (2009). Consumer willingness to pay for locally grown products: The case of South Carolina. Agribusiness: An International Journal, 25(3), 412-426. https://doi.org/10.1002/agr.20210

Chen, L. A., Miranda, B. V., Parcell, J. L., \& Chen, C. (2019). The foundations of institutional-based trust in farmers' markets. Agriculture and Human V alues, 36(3), 395-410. https://doi.org/10.1007/s10460-019-09923-4

Christensen, L. O., Galt, R. E., \& Kendall, A. (2018). Life-cycle greenhouse gas assessment of community supported agriculture in California's Central Valley. Renewable Agriculture and Food Systems, 33(5), 393-405.

https://doi.org/10.1017/S1742170517000254

Christensen, L., Jablonski, B. B., Stephens, L., \& Joshi, A. (2019). Evaluating the economic impacts of farm-to-school procurement. Journal of Agriculture, Food Systems, and Community Development, 8(Suppl. 3), 73-94. https://doi.org/10.5304/jafscd.2019.08C.002 
Connelly, S., Markey, S., \& Roseland, M. (2011). Bridging sustainability and the social economy: Achieving community transformation through local food initiatives. Critical Social Policy, 31(2), 308-324. https://doi.org/10.1177/0261018310396040

Conner, D., Becot, F., \& Imrie, D. (2017). Critical reflections on the USDA Local Food Economics Toolkit. Journal of Agriculture, Food Systems, and Community Development, 7(2), 117-125. https://doi.org/10.5304/jafscd.2017.072.001

Conner, D., King, B., Kolodinsky, J., Roche, E., Koliba, C., \& Trubek, A. (2012). You can know your school and feed it too: Vermont farmers' motivations and distribution practices in direct sales to school food services. Agriculture and Human V alues, 29(3), 321-332. https://doi.org/10.1007/s10460-012-9357-y

Conner, D. S., Sevoian, N., Heiss, S. N., \& Berlin, L. (2014). The diverse values and motivations of Vermont farm to institution supply chain actors. Journal of Agricultural and Environmental Ethics, 27, 695-713. https://doi.org/10.1007/s10806-013-9485-4

Darby, K., Batte, M. T., Ernst, S., \& Roe, B. (2008). Decomposing local: A conjoint analysis of locally produced foods. American Journal of Agricultural Economics, 90(2), 476-486. https://doi.org/10.1111/j.1467-8276.2007.01111.x

Deller, S. C., Lamie, D., \& Stickel, M. (2017). Local foods systems and community economic development. Community Development, 48(5), 612-638. https://doi.org/10.1080/15575330.2017.1373136

Edwards-Jones, G. (2010). Does eating local food reduce the environmental impact of food production and enhance consumer health? Proceedings of the Nutrition Society, 69(4), 582-591. https://doi.org/10.1017/S0029665110002004

Feenstra, G., Allen, P., Hardesty, S., Ohmart, J., \& Perez, J. (2011). Using a supply chain analysis to assess the sustainability of farm-to-institution programs. Journal of Agriculture, Food Systems, and Community Development, 1(4), 6984. https://doi.org/10.5304/jafscd.2011.014.009

Fox, J. M. (2017). Collective approach to complex food system issues: The case of The Ohio State University. Metropolitan Universities, 28(1), 94-112. https://doi.org/10.18060/21470

Franklin, A., Newton, J., \& McEntee, J. C. (2011). Moving beyond the alternative: Sustainable communities, rural resilience and the mainstreaming of local food. Local Environment, 16(8), 771-788. https://doi.org/10.1080/13549839.2011.574685

Goldenberg, M. P., \& Meter, K. (2019). Building multipliers, rather than measuring them: Community-minded ways to develop economic impacts. Journal of Agriculture, Food Systems, and Community Development, 8(Suppl. 3), $153-164$. https://doi.org/10.5304/jafscd.2019.08C.010

Hardesty, S. D. (2008). The growing role of local food markets. American Journal of Agricultural Economics, 90(5), 12891295. https://doi.org/10.1111/j.1467-8276.2008.01219.x

Harris, D., Lott, M., Lakins, V., Bowden, B., \& Kimmons, J. (2012). Farm to institution: Creating access to healthy local and regional foods. Advances in Nutrition, 3(3), 343-349. https://doi.org/10.3945/an.111.001677

Heiss, S. N., Sevoian, N. K., Conner, D. S., \& Berlin, L. (2015). Farm to institution programs: Organizing practices that enable and constrain Vermont's alternative food supply chains. Agriculture and Human Values, 32(1), 87-97. https://doi.org/10.1007/s10460-014-9527-1

Hu, W., Batte, M. T., Woods, T., \& Ernst, S. (2012). Consumer preferences for local production and other value-added label claims for a processed food product. European Review of Agricultural Economics, 39(3), 489-510. https://doi.org/10.1093/erae/jbr039

Jablonski, B. B. R., Schmit, T. M., \& Kay, D. (2016). Assessing the economic impacts of food hubs on regional economies: A framework that includes opportunity cost. Agricultural and Resource Economics Review, 45(1), $143-172$. https://doi.org/10.1017/age.2016.9

Jeuland, M. A., \& Pattanayak, S. K. (2012). Benefits and costs of improved cookstoves: Assessing the implications of variability in health, forest and climate impacts. PloS ONE, 7(2), Article e30338.

https://doi.org/10.1371/journal.pone.0030338

Kerton, S., \& Sinclair, A. J. (2010). Buying local organic food: A pathway to transformative learning. Agriculture and Human V alues, 27(4), 401-413. https://doi.org/10.1007/s10460-009-9233-6 
Keyes, S., Tyedmers, P., \& Beazley, K. (2015). Evaluating the environmental impacts of conventional and organic apple production in Nova Scotia, Canada, through life cycle assessment. Journal of Cleaner Production, 104, 40-51. https://doi.org/10.1016/j.jclepro.2015.05.037

Lee, E. K., Zhang, X., Adler, P. R., Kleppel, G. S., \& Romeiko, X. X. (2020). Spatially and temporally explicit life cycle global warming, eutrophication, and acidification impacts from corn production in the U.S. Midwest. Journal of Cleaner Production, 242, 118465. https://doi.org/10.1016/j.jclepro.2019.118465

Leib, E. B., Abrams, J., Lee, V., Jaffee, A., Foley, C., \& Schwartz, E. (2012). Increasing local food procurement by Massachusetts colleges \& universities (Report). Harvard Food Law and Policy Clinic. https://www.farmtoinstitution.org/sites/default/files/imce/uploads/Increasing-Local-Food-Procurement-byMass-State-Colleges.pdf

Loureiro, M. L., \& Hine, S. E. (2002). Discovering niche markets: A comparison of consumer willingness to pay for local (Colorado grown), organic, and GMO-free products. Journal of Agricultural and Applied Economics, 34(3), 477-487. https://doi.org/10.1017/S1074070800009251

Low, S. A., Adalja, A., Beaulieu, E., Key, N., Martinez, S., Melton, A., Perez, A., Ralston, K., Stewart, H., Suttles, S., Vogel, S., \& Jablonski, B. B. R. (2015). Trends in U.S. local and regional food systems: A report to Congress (Administrative Pub, No. 068). Economic Research Service, U.S. Department of Agriculture. https://www.ers.usda.gov/webdocs/publications/42805/51173 ap068.pdf

Lutz, J., \& Schachinger, J. (2013). Do local food networks foster socio-ecological transitions towards food sovereignty? Learning from real place experiences. Sustainability, 5(11), 4778-4796. https://doi.org/10.3390/su5114778

Macias, T. (2008). Working toward a just, equitable, and local food system: The social impact of community-based agriculture. Social Science Quarterly, 89(5), 1086-1101. https://doi.org/10.1111/j.1540-6237.2008.00566.x

Matts, C., Conner, D. S., Fisher, C., Tyler, S., \& Hamm, M. W. (2015). Farmer perspectives of farm to institution in Michigan: 2012 survey results of vegetable farmers. Renewable Agriculture and Food Systems, 31(1), 60-71. https://doi.org/10.1017/S1742170514000465

Meas, T., Hu, W., Batte, M. T., Woods, T. A., \& Ernst, S. (2015). Substitutes or complements? Consumer preference for local and organic food attributes. American Journal of Agricultural Economics, 97(4), 1044-1071. https://doi.org/10.1093/ajae/aau108

Meehan, M., Yeh, M. C., \& Spark, A. (2008). Impact of exposure to local food sources and food preparation skills on nutritional attitudes and food choices among urban minority youth. Journal of Hunger \& Environmental Nutrition, 3(4), 456-471. https://doi.org/10.1080/19320240802529383

Meier, M. S., Stoessel, F., Jungbluth, N., Juraske, R., Schader, C., \& Stolze, M. (2015). Environmental impacts of conventional agricultural products-Are the differences captured by life cycle assessment? Journal of Environmental Management, 149, 193-208. https://doi.org/10.1016/i.jenvman.2014.10.006

Miller, S. R., \& Mann, J. T. (2020). Measuring the importance of local food in the Chicago foodshed. Journal of Agriculture, Food Systems, and Community Development, 9(2), 101-122. https://doi.org/10.5304/jafscd.2020.092.008

Miller, S. R., Mann, J., Barry, J., Kalchik, T., Pirog, R., \& Hamm, M. W. (2015). A replicable model for valuing local food systems. Journal of Agricultural and Applied Economics, 47(4), 441-461. https://doi.org/10.1017/aae.2015.19

Nalley, L. L., Hudson, D., \& Parkhurst, G. M. (2006). Consistency of consumer valuation under different information sets: An experimental auction with sweet potatoes. Journal of Food Distribution Research, 37(3), 56-67. https://doi.org/10.22004/ag.econ.7063

Ng, S.-L., Bednar, C. M., \& Longley, C. (2010). Challenges, benefits and strategies of implementing a farm-to-cafeteria program in college and university foodservice operations. Journal of Foodservice Management \& Education, 4(1), 22-27. https://fsmec.org/wp-content/uploads/2011/09/NgBednarLongley2010.pdf

O’Hara, J. K., \& Pirog, R. (2013). Economic impacts of local food systems: Future research priorities. Journal of Agriculture, Food Systems, and Community Development, 3(4), 35-42. https://doi.org/10.5304/jafscd.2013.034.003

Ohio State University, The [OSU]. (2016). Purchase of local and sustainable food by 2025. The Ohio State University Panel on Food Sustainability. https://www.osu.edu/assets/downloads/SustainableFoodReport09152016 508.pdf 
OSU. (2018). Purchasing 40 percent local and/or sustainable food by 2025. The Ohio State University Panel on Food Sustainability. https:// si.osu.edu/sites/default/files/Food $\% 20$ Sustainability $\% 20$ Final\%20Report 11-29$18 \% 20 \% 28002 \% 29$.pdf

OSU. (2021a). Columbus campus dining plans. Ohio State University Dining Services. https://dining.osu.edu/diningplans/columbus-campus-dining-plans/

OSU. (2021b). Fringe benefit rates and tuition. Retrieved June 2021 from the OSU Office of Sponsored Programs page: http://osp.osu.edu/development/budgets/fringe-benefit-rates-and-tuition/

Okrent, A. M., \& Alston, J. M. (2012a). The effects of farm commodity and retail food policies on obesity and economic welfare in the United States. American Journal of Agricultural Economics, 94(3), 611-646. https://doi.org/10.1093/ajae/aar138

Okrent, A., \& Alston, J. M. (2012b). The demand for disaggregated food-away-from-home and food-at-home products in the United States (ERR-139). U.S. Department of Agriculture, Economic Research Service. https://www.ers.usda.gov/publications/pub-details/?pubid=45006

Porter, J., Conner, D., Kolodinsky, J., \& Trubek, A. (2017). Get real: An analysis of student preference for real food. Agriculture and Human Values, 34(4), 921-932. https://doi.org/10.1007/s10460-017-9785-9

Romeiko, X. X., Lee, E. K., Sorunmu, Y., \& Zhang, X. (2020). Spatially and temporally explicit life cycle environmental impacts of soybean production in the U.S. Midwest. Environmental Science \& Technology, 54(8), 4758-4768. https://doi.org/10.1021/acs.est.9b06874

Sieverding, H., Kebreab, E., Johnson, J. M. F., Xu, H., Wang, M., Del Grosso, S., Bruggeman, S., Stewart, C. E., Westhoff, S., Ristau, J., Kumar, S., \& Stone, J. J. (2020). A life cycle analysis (LCA) primer for the agricultural community. Agronomy Journal, 112(5), 3788-3807. https://doi.org/10.1002/agj2.20279

Socolof, M. L., Overly, J. G., Kincaid, L. E., \& Geibig, J. R. (2001). Desktop computer displays: A life-cycle assessment, Volume 1 (Pub. EPA-744-R-01-004a). U.S. Environmental Protection Agency. https://www.epa.gov/sites/production/files/2015-04/documents/ch3.pdf

Thilmany McFadden, D., Conner, D., Deller, S., Hughes, D., Meter, K., Morales, A., Schmit, T., Swenson, D., Bauman, A., Philips Goldenberg, M., Hill, R., Jablonski, B. B. R., \& Tropp, D. (2017). The economics of local food systems: A toolkit to guide community discussions, assessments, and choices. U.S. Department of Agriculture, Agricultural Marketing Service. https://localfoodeconomics.com/wp-content/uploads/2017/03/Toolkit-Designed-FINAL-UPDATED-03-72017.pdf

U.S. Department of Agriculture, National Agricultural Statistics Service [USDA NASS]. (2016). Direct farm sales of food: Results from the 2015 Local Food Marketing Practices Survey. U.S. Department of Agriculture, National Agricultural Statistics Service. https://www.nass.usda.gov/Publications/Highlights/2016/LocalFoodsMarketingPractices Highlights.pdf

USDA NASS. (2019). Market value of agricultural products sold including landlord's share, food marketing practices, and value-added products: 2017 and 2012.

https://www.nass.usda.gov/Publications/AgCensus/2017/Full Report/Volume 1, Chapter 1 US/st99 10002 0002.pdf

USDA NASS. (2020). Quick Stats. http:/ / quickstats.nass.usda.gov/

Uzunogullari, D. E. (2018). Assessing vegetable demand of the City of Toledo using life cycle assessment [Master's thesis, University of Toledo]. OhioLINK Electronic Theses \& Dissertations Center. https://etd.ohiolink.edu/apexprod/rws olink/r/1501/10?clear=10\&p10 accession num=toledo15246052367171 $\underline{13}$

Watson, P., Wilson, J., Thilmany, D., \& Winter, S. (2007). Determining economic contributions and impacts: What is the difference and why do we care? Journal of Regional Analysis and Policy, 37(2), 140-146. https://irap.scholasticahq.com/article/9291

Winfree, J., \& Watson, P. (2017). The welfare economics of "buy local.” American Journal of Agricultural Economics, 99(4), 971-987. https://doi.org/10.1093/ajae/aaw104 